\title{
Journal of Advanced Ceramics: New Journal, New Start
}

\author{
Longtu LI \\ Editor-in-Chief, Journal of Advanced Ceramics \\ State Key Laboratory of New Ceramic and Fine Processing, Tsinghua University, Beijing 100084, China
}

(C) The Author(s) 2012. This article is published with open access at Springerlink.com

Welcome to the inaugural issue of the Journal of Advanced Ceramics $(J A C)$, a new international journal administered by the State Key Laboratory of New Ceramic and Fine Processing (SKL-NCFP) at Tsinghua University, Beijing, China. $J A C$ is jointly-published by Tsinghua University Press and Springer and will provide an exciting venue for rapid disclosure of significant research in ceramics.

Advanced ceramics is one of the most important new inorganic non-metallic materials. It plays an important role in the development of electronic information, new energy, communication, automobile, bio-medicine, environmental sciences, aeronautics and space technology, and advanced manufacturing, among other applications. In fact, owing to the broad impact of advanced ceramics on both fundamental science and numerous emerging technologies, global interest in ceramics continues to grow. The field of study attracts not only ceramists but also many physicists, chemists, mechanists and other materials scientists worldwide. Advanced ceramics encompasses a broad range and diverse set of materials, including functional ceramics (dielectrics, ferroelectrics, piezoelectrics, pyroelectrics, semiconductive, conductive, magnetic, multiferroics, superconductive, etc.), structural ceramics (oxide, nitride, carbide, boride, silicide, etc.), as well as ceramic-based composite.

The Journal of Advanced Ceramics will publish new results and significant findings of theoretical and experimental studies related to the structure, processing, properties and applications of advanced ceramics and ceramic-based composite. Papers may cover any of the branches of ceramic science and technology. Original, high quality research papers and review articles are welcomed and will be subjected to peer-review process. We strive to maintain high scientific standards and have a broad international coverage. The Editorial Board will make every effort to serve the readers and authors within the broader ceramics field from all over the world.

We hope that the $J A C$ will provide a home for research focused on various aspects of advanced ceramics materials, a forum for academic exchange of novel ideas and exciting discovery from professors, scientists, engineers and students of material sciences and technologies. I am extremely enthusiastic about the future of advanced ceramics and the role that $J A C$ will play in communicating discoveries and advancements in this dynamic and multidisciplinary field. We look forward to working with all of you to make $J A C$ an impactful journal in this exciting and vibrant discipline.

Open Access This article is distributed under the terms of the Creative Commons Attribution License which permits any use, distribution, and reproduction in any medium, provided the original author(s) and source are credited. 